\title{
Penerapan produksi bersih dan penilaian daur hidup industri kecil menengah pengolahan kopi CV. Gunung Betung
}

\author{
[Cleaner production implementation and life cycle assessment in a small and medium coffee industry \\ CV Gunung Betung]
}

Febilian Adiwinata', Suprihatin², dan Mulyorini Rahayuningsih²

1 Program Studi Pascasarjana Teknik Industri Pertanian, Fakultas Teknologi Pertanian, IPB University, Bogor, Indonesia

${ }^{2}$ Departemen Teknologi Industri Pertanian, IPB University, Bogor, Indonesia

*Email korespondensi : adiwinata.febilian@gmail.com

Diterima : 19 Januari 2021, Disetujui : 8 Juli 2021, DOI : http://dx.doi.org/10.23960/jtihp.v26i2.99-108

\begin{abstract}
Coffee is one of Indonesia's leading commodity that has the potential to be developed for agro-industry. High coffee production has encouraged the establishment of a small and medium coffee industry. The purpose of this study is to analyze possible strategies for implementing cleaner production and evaluate the impact on the environment using Life Cycle Assessment (LCA) method with a gate to gate scope. The stages of cleaner production research used quick scan techniques, source identification, cause evaluation and option generation implementation. LCA research stages with the determination of the objectives and scope of research, inventory analysis, environmental impact assessment and implementation of improvements. Greenhouse gases (GHG) emission was assessed as an environmental impact parameter. The results showed the alternative potential for cleaner production that was applied the manufacture of drying domes (Payback Period/PBP) 3.18 months with an investment ofRp. 2,285,000), procurement of generator machines (PBP 1.16 months with an investment of Rp. 5,860,000), making air circulation in roasting room (PBP 0.07 months with an investment of Rp. 1,268,000), making of solid waste composting reactor (PBP 2.18 months with an investment of Rp. 3,440,000) and addition packing equipment (PBP 0.45 month with an investment of Rp. 3.057.000). The results of the $L C A$ analysis show that $1,000 \mathrm{Kg}$ of dry-processed coffee requires energy of $869.92 \mathrm{MJ}$ and produces $\mathrm{GHG}$ emissions of $95.58 \mathrm{Kg} \mathrm{CO}_{2}$ eq / ton coffee fruits or $0.42 \mathrm{Kg} \mathrm{CO}_{2}$ eq / $\mathrm{Kg}$ coffee powder equal to $2.389 \mathrm{Kg} \mathrm{CO}_{2}$ eq/month and $28.674 \mathrm{Kg} \mathrm{CO}_{2}$ eq/year.
\end{abstract}

Key words : environmental impact assessment, life cycle assessment, small coffee industries

\section{ABSTRAK}

Kopi merupakan komoditas agroindustri unggulan Indonesia yang potensial untuk dikembangkan. Produksi kopi yang tinggi mendorong berdirinya industri pengolahan kopi skala kecil dan menengah. Tujuan penelitian ini adalah menganalisis kemungkinan strategi penerapan produksi bersih dan mengevaluasi dampak lingkungan yang ditimbulkan dengan menggunakan metode Life Cycle Assessment (LCA) lingkup gate to gate. Tahapan penelitian produksi bersih dengan teknik quick scan yaitu identifikasi akar masalah, evaluasi penyebab dan penerapan opsi perbaikan. Tahapan LCA adalah penetapan tujuan serta cakupan kegiatan, analisis inventori, penilaian dampak lingkungan dan penerapan perbaikan. Dampak lingkungan yang dianalisis adalah emisi Gas Rumah Kaca (GRK). Hasil penelitian menunjukkan potensi alternatif produksi bersih yang diterapkan adalah pembuatan dome penjemuran (PBP 3,18 bulan dan investasi Rp. 2.285.000), pengadaan mesin genset (PBP 1,16 bulan dan investasi Rp. 5.860.000), pembuatan sirkulasi udara ruang roasting (PBP 0,07 bulan dan investasi Rp. 1.268.000), pembuatan reaktor pengomposan limbah padat (PBP 2,18 bulan dan investasi Rp. 3.440.000) dan penambahan alat packing (PBP 0,45 bulan dan investasi Rp. 3.057.000). Hasil analisis LCA menunjukkan bahwa $1.000 \mathrm{Kg}$ buah kopi yang diolah secara kering membutuhkan energi sebesar 869,92 MJ dan menghasilkan emisi GRK sebesar 95,58 $\mathrm{Kg} \mathrm{CO}_{2} \mathrm{eq} /$ ton buah kopi atau $0,42 \mathrm{Kg} \mathrm{CO}$ eq/ kg kopi bubuk yang setara dengan $2,389 \mathrm{Kg} \mathrm{CO}_{2}$ eq / bulan dan $28,674 \mathrm{Kg} \mathrm{CO}$ eq/ tahun.

Kata kunci :Industri kopi skala kecil, life cycle assessment, analisis dampak lingkungan

\section{Pendahuluan}

Indonesia merupakan negara produsen kopi urutan ke empat di dunia setelah Brazil, Vietnam, dan Kolombia (AEKI, 2014) namun sebagai konsumen berada pada urutan ketujuh (ICO, 2017). Data yang 
dilaporkan oleh Ditjenbun (2019) menunjukkan luas area komoditas kopi di Indonesia sebesar 1,24 juta Ha dan total produksi sebesar 729,074 ribu ton per tahun. Provinsi penghasil kopi terbesar kedua di Indonesia adalah Provinsi Lampung yang memiliki luas area perkebunan kopi sebesar $157.682 \mathrm{Ha}$ dengan total produksi sebesar 107.219 ton per tahun. Sedangkan total produksi di kota Bandar Lampung sebesar 231 ton per tahun (BPS, 2018).

Menurut Ledy et al. (2019), produksi kopi yang tinggi mendorong berdirinya Industri Kecil Menengah (IKM) pengolahan kopi, salah satu diantaranya adalah IKM pengolahan kopi CV. Gunung Betung. Produksi pengolahan kopi memberikan dampak negatif terhadap kualitas lingkungan. Menurut Diyarma \& Bantacut (2019), IKM kopi dengan kapasitas bahan baku $1000 \mathrm{Kg}$ mampu menghasilkan $500 \mathrm{Kg}$ limbah padat. Sampai dengan saat ini belum ditemukan penelitian yang membahas analisis produksi bersih dan penilaian daur hidup Industri Kecil Menengah (IKM) pengolahan kopi di Bandar Lampung, sehingga dampak terhadap lingkungan yang ditimbulkan dari proses pengolahan kopi tersebut belum diketahui. Penerapan produksi bersih dapat menurunkan dampak lingkungan IKM pengolahan kopi sedangkan dampak lingkungan dari proses produksi IKM pengolahan kopi dapat dihitung dengan metode LCA (Diyarma \& Bantacut, 2019).

Produksi bersih merupakan salah satu cara guna tercapainya peningkatan efisiensi proses produksi, penerapan teknik recycle dan reuse, peluang substitusi bahan baku yang ekonomis dan pengendalian sistem operasi serta prosedur kerja (Adiansyah et al., 2019). Menurut Sirait et al. (2019) tujuan produksi bersih untuk mengurangi terbentuknya produk samping atau bahan pencemar. Sedangkan menurut Hakim (2018), produksi bersih bertujuan untuk menghasilkan produk yang berkelanjutan dan tidak berbahaya. Menurut Nisa et al. (2016), penggunaan energi yang sesuai dari alternative penerapan produksi bersih mampu meminimalisir emisi.

Penilaian daur hidup adalah metode yang digunakan untuk menganalisis dan mengukur siklus hidup suatu proses dari penerimaan bahan baku sampai menjadi produk (Diyarma \& Bantacut, 2019), terdiri dari empat tahapan yaitu penetapan batasan, analisis ketersediaan, perhitungan dampak dan interpretasi hasil (De Marco et al., 2018). Metode penilaian daur hidup memberikan estimasi dampak yang dihasilkan dalam satu siklus hidup produk dan dapat diketahui tahapan mana yang memberikan dampak terbesar (Phrommarat, 2019). Hal ini akan menjadi informasi yang bermanfaat dalam pengembangan produk kopi Indonesia khususnya di Bandar Lampung secara komprehensif dengan menganalisis dan menghitung dampak lingkungan dan nilai emisinya. Tujuan penelitian ini menganalisis kemungkinan strategi penerapan produksi bersih dan mengevaluasi dampak yang ditimbulkan terhadap lingkungan menggunakan pendekatan LCA dengan lingkup gate to gate.

\section{Bahan dan Metode}

\section{Metode Penelitian}

Kajian produksi bersih pada penelitian ini dilakukan di Industri Kecil Menengah (IKM) kopi CV. Gunung Betung, Bandar Lampung dengan produk utama yang dihasilkan yaitu kopi bubuk robusta dari biji kopi pilihan.

\section{Produksi Bersih (Cleaner Production)}

Tahap kajian produksi besih (Gambar 1), analisis pendahuluan/quick scan menghasilkan luaran berupa akar masalah terjadinya penurunan kualitas lingkungan, jumlah energi yang dibutuhkan dan limbah yang dihasilkan (Edowai \& Tahoba, 2018). Metode quick scan berfokus kepada audit pengkajian suatu bagian proses produksi yang dinilai memiliki peluang besar untuk diterapkannya perbaikan (Fitriyanti, 2018) dari aspek teknis, aspek finansial dan aspek lingkungan sesuai dengan konsep produksi bersih (Sirait et al., 2019). 
Analisis yang dilakukan berfokus pada lima komponen yaitu: bahan input, teknologi, proses produksi, dan output (produk serta limbah). Alternatif pilihan perbaikan yang akan dihasilkan berupa: substitusi input, pembaruan teknologi, good housekeeping, inovasi produk dan on-sitereuse (Fauziet al., 2018). Menurut Novita et al. (2018), penerapan konsep produksi bersih dapat memberikan manfaat kepada industri diantaranya ialah mencegah over budget biaya produksi, meminimalisir limbah, memaksimalkan produktivitas, efisiensi energi, penanganan limbah dan produk samping. Pemilihan alternatif produksi bersih didasarkan pada analisis teknis, lingkungan dan finansial. Metode standar yang digunakan dalam analisis finansial yaitu perhitungan payback periode(PBP) dengan kriteria waktu PBP dibawah satu tahun.

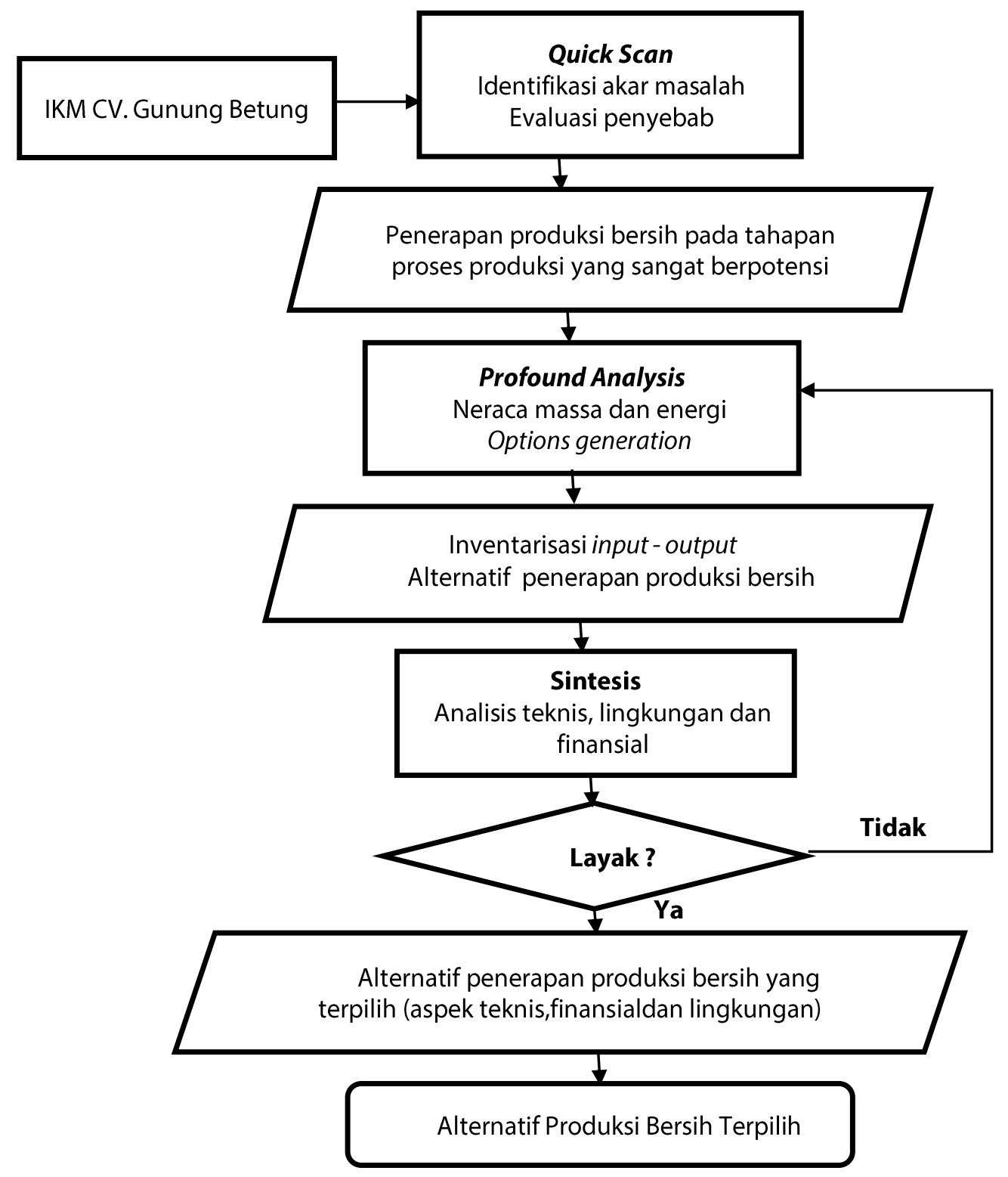

Gambar 1. Diagram Alir Pelaksanaan Penelitian Cleaner Productionreuse (Fauzi et al., 2018)

\section{Penilaian Daur Hidup (Life Cycle Assessment)}

Penerapan prinsip kerja penilaian daur hidup (Gambar 2) mengacu pada prinsip ISO 14040:2006 yang terdiri dari empat tahap, yaitu penetapan batasan dan tujuan, inventarisasi input dan output (life cycle inventory analysis), penilaian dampak (life cycle impact assessment), dan interpretasi (life cycle interpretation) (Roy et al., 2019). Data hasil analisis LCA akan digunakan untuk menghitung dampak negatif terhadap lingkungan, optimalisasi penggunaan bahan baku pada unit kerja proses produksi 
sehingga bisa memungkinkan untuk meningkatkan kinerja dalam perusahaan pengolahan kopi (Fadhil et al., 2017).

Analisis inventori merupakan salah satu tahapan LCA yang berisi data aliran bahan dan energi yang merepresentasikan input dan output dari daur hidup produk kopi (Diyarma \& Bantacut, 2019). Data yang dibutuhkan pada penelitian ini adalah data primer dan sekunder. Data primer yang diperoleh dari observasi langsung di lapangan, dokumen catatan perusahaan, dan wawancara dengan pemilik industri. Data sekunder berupa jurnal penelitian terkait dan tesis yang telah dipublikasikan sebelumnya. Data lainnya diperoleh dari hasil perhitungan dengan beberapa asumsi. Data yang dibutuhkan pada analisis inventori LCA yaitu tahap pemanenan buah kopi, proses produksi kopi sampai penyimpanan produk di IKM (Maina, 2017). Batasan sistem proses penelitian tersaji dalam Gambar 3.

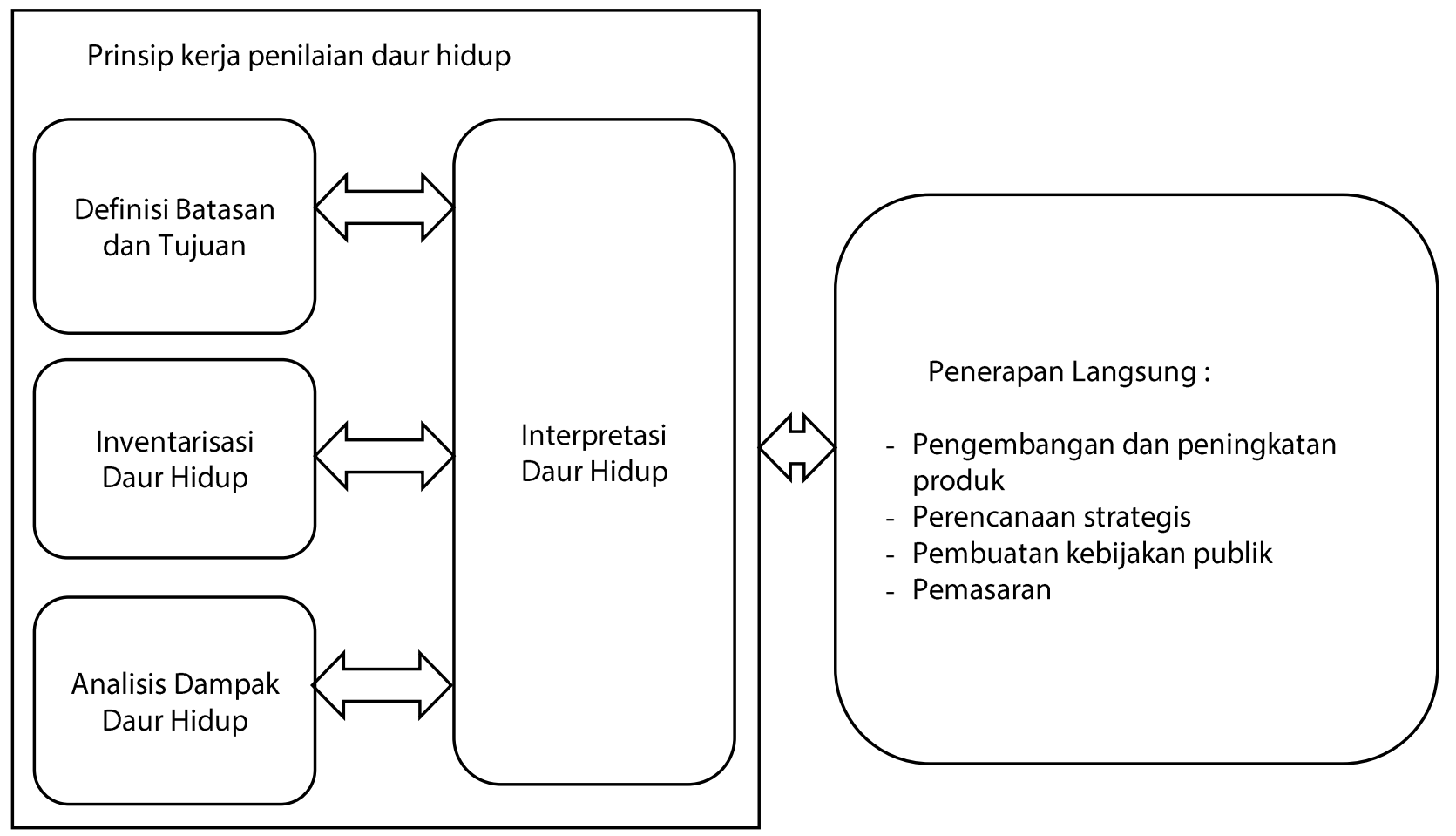

Gambar 2. Diagram alir prinsip kerja kajian metode LCA (ISO 2006)

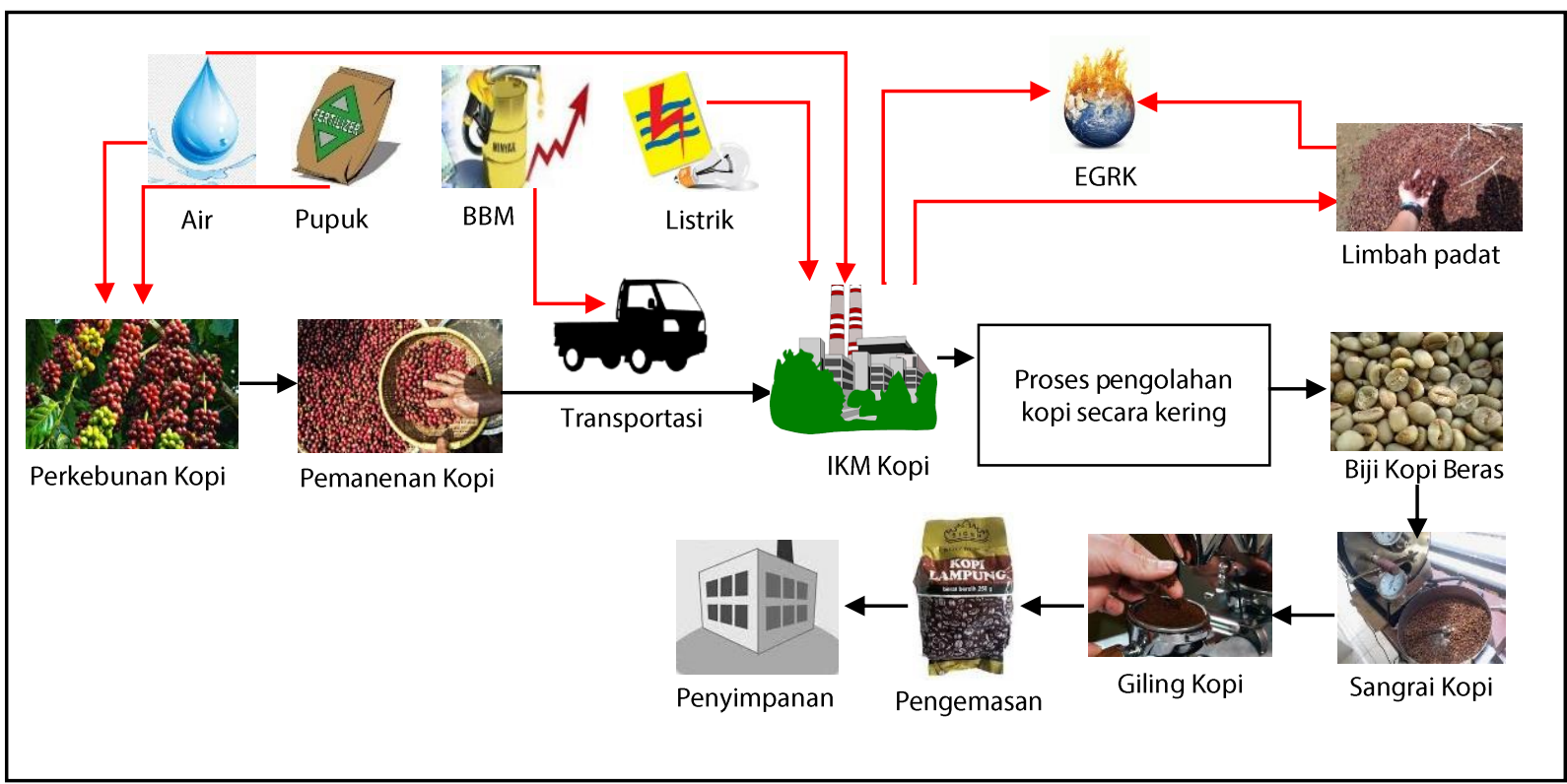

Gambar 3. Batasan sistem proses penelitian LCA di IKM pengolahan kopi (Salomone, 2018) 
Perhitungan emisi Gas Rumah Kaca (GRK) menggunakan persamaan Intergovernmental Panel on Climate Change (IPCC, 2006). Sebagai salah satu contoh perhitungan untuk emisi GRK dari penggunaan bahan bakar premium tersaji pada Rumus 1.

$$
\mathrm{Emisi} \mathrm{CO}_{2}(\text { premium })=Q F x \mathrm{NK} \times \mathrm{FE}
$$

Keterangan :

$\mathrm{QF}=$ Konsumsi premium (Liter)

$\mathrm{NK}=$ Nilai kalor bersih $(0,000041 \mathrm{TJ} /$ Liter $)$

$\mathrm{FE}=$ Faktor emisi $\left(69.300 \mathrm{CO}_{2} / \mathrm{TJ}\right)$

\section{Penilaian Dampak Lingkungan (Life Cycle Impact Assesment)}

Analisis inventori bertujuan untuk menganalisis atau mengevaluasi dampak lingkungan yang dihasilkan dari aktivitas IKM pengolahan kopi (Siregar et al., 2019). Perhitungan analisis dampak tersebut dapat dikelompokkan berdasarkan kontribusi dampaknya terhadap emisi GRK yang dianalisis berdasarkan kandungan $\mathrm{CO}_{2}, \mathrm{~N}_{2} \mathrm{O}$, dan $\mathrm{CH}_{4}$ (Hassard et al., 2016). Menurut (Pramono \& Sadmaka, 2018) emisi GRK terdiri daritiga jenis sumber gas yaitu $\mathrm{N}_{2} \mathrm{O}, \mathrm{CH}_{4}$, dan $\mathrm{CO}_{2}$ dari penggunaan bahan bakar fosil dan limbah. Menurut Nugraha et al. (2018) Global Warming Potential merupakan nilai yang relatif sama dengan $\mathrm{CO}_{2}$, setiap $1 \mathrm{Kg}$ gas metana $\left(\mathrm{CH}_{4}\right)$ memiliki nilai GWP sebesar $28 \mathrm{Kg} \mathrm{CO}_{2}$ eq dan gas nitrooksida $\left(\mathrm{N}_{2} \mathrm{O}\right)$ memiliki nilai GWP sebesar $265 \mathrm{Kg} \mathrm{CO}_{2} \mathrm{eq}$.

\section{Hasil dan Pembahasan}

\section{Alternatif Produksi Bersih yang Dapat Diterapkan}

Secara umum CV. Gunung Betung memiliki beberapa alternatif guna mengatasi permasalahan yang ada, setelah dilakukan identifikasi dari setiap tahapan proses produksi, maka terpilih beberapa alternatif produksi bersih yang akan diterapkan. Tabel 1 menunjukkan potensi penerapan alternatif produksi bersih di IKM kopi CV. Gunung Betung dengan PBP dibawah satu tahun, serta Input dan Output proses produksi kopi secara kering CV. Gunung Betung disajikan dalam Tabel 2.

Tabel 1. Potensi penerapan produksi bersih yang terpilih

\begin{tabular}{|c|c|c|c|c|}
\hline Potensi Produksi Bersih & Tujuan & $\begin{array}{l}\text { Analisis } \\
\text { Teknis }\end{array}$ & Analisis Lingkungan & $\begin{array}{c}\text { Payback Period } \\
\text { (PBP) }\end{array}$ \\
\hline $\begin{array}{l}\text { Pembuatan dome } \\
\text { penjemuran buah kopi } \\
\text { dengan drying beds }\end{array}$ & $\begin{array}{l}\text { Mempercepat proses } \\
\text { pengeringan dan } \\
\text { mengurangi kerusakan } \\
\text { buah kopi akibat hujan }\end{array}$ & Sedang & $\begin{array}{l}\text { Mengurangi reject } \\
\text { buah kopi \& limbah } \\
\text { padat }\end{array}$ & $\begin{array}{l}\text { 3,18 bulan } \\
\text { Biaya : Rp. } 2.285 .000\end{array}$ \\
\hline Pengadaan mesin genset & $\begin{array}{l}\text { Menggantikan suplai } \\
\text { listrik jika (listrik PLN } \\
\text { mati) agar proses } \\
\text { produksi tetap } \\
\text { berjalan }\end{array}$ & Sedang & $\begin{array}{l}\text { Mengurangi } \\
\text { kerusakan pada biji } \\
\text { kopi akibat proses } \\
\text { produksi yang } \\
\text { tertunda }\end{array}$ & $\begin{array}{l}\text { 1,16 bulan } \\
\text { Biaya : Rp. } 5.860 .000\end{array}$ \\
\hline $\begin{array}{l}\text { Pembuatan sirkulasi udara } \\
\text { ruang roasting dengan } \\
\text { exhaust fan }\end{array}$ & $\begin{array}{l}\text { Melindungi pekerja } \\
\text { dari penyakit Infeksi } \\
\text { Saluran Pernafasan } \\
\text { Akut (ISPA) }\end{array}$ & Mudah & $\begin{array}{l}\text { Melindungi pekerja } \\
\text { agar tetap produktif }\end{array}$ & $\begin{array}{l}0,07 \text { bulan } \\
\text { Biaya : Rp. } 1.268 .000\end{array}$ \\
\hline $\begin{array}{l}\text { Pembuatan reactor } \\
\text { pengomposan limbah } \\
\text { padat }\end{array}$ & $\begin{array}{l}\text { Mempercepat proses } \\
\text { pengomposan dan } \\
\text { menghasilkan kompos } \\
\text { yang baik }\end{array}$ & Sedang & $\begin{array}{l}\text { Mengurangi limbah } \\
\text { padat dan emisi GRK }\end{array}$ & $\begin{array}{l}2,18 \text { bulan } \\
\text { Biaya : Rp. } 3.440 .000\end{array}$ \\
\hline $\begin{array}{l}\text { Penambahan alat packing } \\
\text { (timbangan digital dan } \\
\text { impulse sealer) }\end{array}$ & $\begin{array}{l}\text { Mempercepat proses } \\
\text { pengemasan agar } \\
\text { tidak over loading }\end{array}$ & Mudah & $\begin{array}{l}\text { Mencegah kerusakan } \\
\text { produk kopi bubuk }\end{array}$ & $\begin{array}{l}0,45 \text { bulan } \\
\text { Biaya : Rp. } 3.057 .000\end{array}$ \\
\hline
\end{tabular}


Tabel 2. Input dan output proses produksi kopi secara kering

\begin{tabular}{|c|c|c|c|c|c|}
\hline \multirow{2}{*}{\multicolumn{2}{|c|}{ Tahapan Proses }} & \multirow{3}{*}{$\begin{array}{c}\begin{array}{c}\text { Input } \\
\text { (Kg) }\end{array} \\
1000\end{array}$} & \multirow{2}{*}{$\begin{array}{c}\begin{array}{c}\text { Output } \\
\text { (Kg) }\end{array} \\
\end{array}$} & \multicolumn{2}{|c|}{ Limbah } \\
\hline & & & & Padat (Kg) & Teruapkan (L)* \\
\hline Perkebunan kopi & Pupuk organik & & & - & - \\
\hline Pemanenan kopi & Petik buah merah & - & 1000 & - & - \\
\hline \multirow{2}{*}{$\begin{array}{l}\text { Transportasi hasil panen } \\
\text { Sortasi manual I (buah } \\
\text { hijau) }\end{array}$} & Bauh kopi hasil panen & 1000 & 1000 & - & - \\
\hline & Buah kopi pilihan & 1000 & 992 & 8 & - \\
\hline \multirow{2}{*}{$\begin{array}{l}\text { Pengeringan / } \\
\text { penjemuran } \\
\text { Pengupasan kulit tanduk } \\
\text { (hulling) }\end{array}$} & $\begin{array}{l}\text { Buah kopi kering/ biji kopi } \\
\text { labu }\end{array}$ & 992 & 529 & - & 463 \\
\hline & Biji kopi beras / green bean & 529 & 291 & 238 & - \\
\hline \multirow{2}{*}{$\begin{array}{l}\text { Sortasi manual II (green } \\
\text { bean reject) }\end{array}$} & Green bean pilihan & 291 & 286 & - & - \\
\hline & $\begin{array}{l}\text { Green bean cacat } \\
\text { Kulit tanduk }\end{array}$ & & 3 & 2 & - \\
\hline Penyangraian (roasting) & $\begin{array}{l}\text { Green bean matang } \\
\text { (medium to dark) }\end{array}$ & 286 & 232 & - & 54 \\
\hline \multirow{3}{*}{$\begin{array}{l}\text { Pendinginan I (cooling) } \\
\text { Penggilingan (grinding) } \\
\text { Pendinginan II (cooling) }\end{array}$} & Green bean pilihan & 232 & 231 & - & 1 \\
\hline & Bubuk kopi 0,8 mesh & 231 & 230 & 1 & - \\
\hline & Bubuk kopi siap kemas & 230 & 229 & - & 1 \\
\hline \multirow{3}{*}{$\begin{array}{l}\text { Pengemasan (packing) } \\
\text { Penyimpanan (storage) }\end{array}$} & Kopi bubuk dalam kemasan & 229 & 228,5 & 0,5 & - \\
\hline & Kopi bubuk siap jual & 228,5 & 228,5 & - & - \\
\hline & mlah & & 228,5 & 249,5 & 519 \\
\hline
\end{tabular}

Keterangan : *asumsi masa jenis air yang teruapkan dalam kondisi STP

Tabel 3. Total kebutuhan energi CV. Gunung Betung kapasitas 1 ton buah kopi per hari.

\begin{tabular}{lcccccccc}
\hline & \multicolumn{7}{c}{ Sumber Energi dalam Mega Joule } \\
\cline { 2 - 8 } \multicolumn{1}{c}{ Tahapan proses } & $\begin{array}{c}\text { Premium } \\
\text { (L) }\end{array}$ & $\begin{array}{c}\text { LPG } \\
\text { (Kg) }\end{array}$ & $\begin{array}{c}\text { Listrik } \\
\text { (Kwh) }\end{array}$ & $\begin{array}{c}\text { Premium } \\
\text { (MJ) }\end{array}$ & $\begin{array}{c}\text { LPG } \\
\text { (MJ) }\end{array}$ & $\begin{array}{c}\text { Listrik } \\
\text { (MJ) }\end{array}$ & $\begin{array}{c}\text { Total } \\
\text { (MJ) }\end{array}$ & $\begin{array}{c}\text { Persentase } \\
\text { (\%) }\end{array}$ \\
\hline Transportasi & 5 & - & - & 173.3 & - & - & 173.3 & 19,11 \\
Sortasi Manual I & - & - & 0.48 & - & - & 1.728 & 1.728 & 0,2 \\
Penjemuran & - & - & - & - & - & - & - & - \\
Pengupasan kulit & 5.5 & - & - & 190.63 & - & - & 190.63 & 22,14 \\
Sortasi Manual II & - & - & 0.48 & - & - & 1.728 & 1.728 & 0,2 \\
Penyangraian & - & 6 & 3.44 & - & 288 & 12.38 & 300.38 & 35 \\
Pendinginan I & - & - & 1.38 & - & - & 4.95 & 4.95 & 0,57 \\
Penggilingan & 5 & & 0.48 & 173.3 & & 1.728 & 175.028 & 20,19 \\
Pendinginan II & - & - & 1.38 & - & - & 4.95 & 4.95 & 0,57 \\
Pengemasan & - & - & 3.41 & - & - & 12.28 & 12.28 & 1,43 \\
Penyimpanan & - & - & 1.38 & - & - & 4.95 & 4.95 & 0,57 \\
$\quad$ Jumlah & $\mathbf{1 5 . 5}$ & $\mathbf{6}$ & $\mathbf{1 2 . 4 3}$ & $\mathbf{5 3 7 . 2 3}$ & $\mathbf{2 8 8}$ & $\mathbf{4 4 . 6 9}$ & $\mathbf{8 6 9 . 9 2}$ & $\mathbf{1 0 0}$ \\
\hline
\end{tabular}

Keterangan : Asumsi (IPCC, 2006)

$\begin{array}{ll}\text { Premium } & : 34,66 \mathrm{MJ} / \text { Liter } \\ \text { LPG } & : 48 \mathrm{MJ} / \mathrm{Kg} \\ \text { Listrik } & : 3,6 \mathrm{MJ} / \mathrm{Kwh}\end{array}$

Penjabaran data pada Tabel 3 menjelaskan kebutuhan sumber energi pada proses produksi CV. Gunung Betung dan total kebutuhan energi yang dibutuhkan yaitu sebesar 869,92 MJ/ton buah kopi yang diolah. Proses pengupasan kulit tanduk buah kopi yang paling besar membutuhkan energi yaitu $22,14 \%$, kemudian proses penggilingan biji kopi sebesar 20,19\% dan transportasi sebesar 19,11\%. Persentase kebutuhan energi ditiap tahapan proses disajikan pada Gambar 4. 


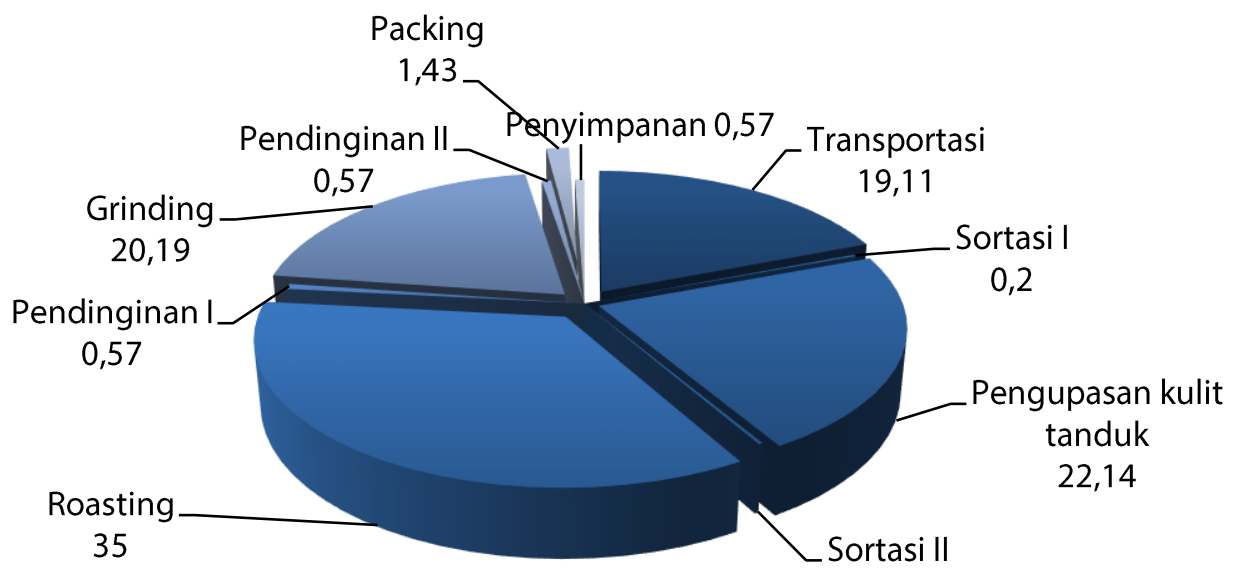

0,2
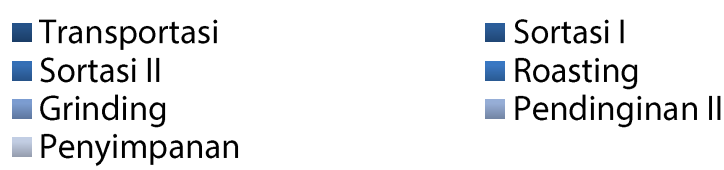

- Pengupasan kulit tanduk Pendinginan I Packing

Gambar 4. Diagram persentase penggunaan energi pengolahan kopi robusta secara kering

Analisis perhitungan dampak Emisi GRK proses pengolahan kopi robusta secara kering di CV. Gunung Betung disajikan dalam Tabel 4 dan Tabel 5, pada sektor proses produksi menjadi penyumbang emisi terbesar, hal ini disebebkan oleh penggunaan bahan bakar fosil dan energi listrik yang tinggi (Echeverria \& Nuti, 2017). Penggunaan energi ini menyumbang $68,83 \mathrm{Kg}-\mathrm{CO}_{2} \mathrm{eq} /$ ton kopi yang diproses. Nilai ini menunjukkan bahwa $72 \%$ potensi pemanasan global yang dihasilkan dalam proses produksi kopi robusta secara kering di CV. Gunung Betung berasal dari kegiatan dalam pabrik.

Tabel 4. Emisi GRK CV. Gunung Betung kapasitas produksi 1 ton buah kopi per hari

\begin{tabular}{|c|c|c|c|c|c|}
\hline \multirow[t]{2}{*}{ Tahapan proses } & \multicolumn{3}{|c|}{ Emisi GRKCO ${ }_{2}$ eq (Kg) } & \multirow{2}{*}{$\begin{array}{c}\text { Total } \\
\mathrm{CO}_{2} \mathrm{eq}(\mathrm{Kg})\end{array}$} & \multirow{2}{*}{$\begin{array}{c}\text { Unit proses } \\
(\%)\end{array}$} \\
\hline & $\mathrm{CO}_{2}$ & $\mathrm{CH}_{4}$ & $\mathrm{~N}_{2} \mathrm{O}$ & & \\
\hline Pemupukan & - & - & 12,46 & 12,46 & 13,03 \\
\hline Transportasi & 14,21 & 0,06 & 0,03 & 14,30 & 14,96 \\
\hline Sortasi manual I & 0,84 & - & - & 0,84 & 0,88 \\
\hline Pengupasan kulit tanduk & 15,63 & 0,06 & 0,04 & 15,73 & 16,46 \\
\hline Sortasi manual II & 0,84 & - & - & 0,84 & 0,88 \\
\hline Roasting / peyangraian & 23,91 & 0,04 & 0,01 & 23,96 & 25,07 \\
\hline Pendinginan I & 2,4 & - & - & 2,40 & 2,51 \\
\hline Grinding / penggilingan & 14,21 & 0,06 & 0,03 & 14,30 & 14,96 \\
\hline Pendinginan II & 2,4 & - & - & 2,40 & 2,51 \\
\hline Packing / pengemasan & 5,96 & - & - & 5,96 & 6,24 \\
\hline Penyimpanan & 2,4 & - & - & 2,40 & 2,51 \\
\hline Total & 82,80 & 0,22 & 12,57 & 95,58 & 100 \\
\hline
\end{tabular}

Proses pemupukkan diperkebunan menyumbang $12,46 \mathrm{Kg}-\mathrm{CO}_{2} \mathrm{eq} / \mathrm{ton}$ buah kopi, proses perkebunan kopi menghasilkan emisi GRK yang rendah karena pada proses ini menggunakan pupuk kandang olahan dari kotoran hewan yang dicampur dengan limbah padat kulit buah kopi (Velmourougane, 2016) yang memiliki nilai N sebesar 2,34\% (Hartatik \& Widowati 2006) atau 2,31\% (Zhou et al., 2017) dan sebagian besar unsur $\mathrm{N}$ yang terdapat dalam pupuk kandang dapat terurai selama proses pemupukkan (Chemura et al., 2017). Begitu pula dengan proses transportasi, dimana pada proses ini untuk mengangkut $1.000 \mathrm{Kg}$ buah kopi hasil panen dari perkebunan menuju pabrik menghasilkan $14,30 \mathrm{Kg}-\mathrm{CO}_{2} \mathrm{eq} /$ ton. Emisi yang terbentuk ini berupa emisi $\mathrm{CO}_{2} 82,80 \mathrm{Kg}$ setara dengan $82,80 \mathrm{Kg}-\mathrm{CO}_{2} \mathrm{eq}, \mathrm{CH}_{4} 0,008 \mathrm{Kg}$ setara dengan 0,22 $\mathrm{Kg}-\mathrm{CO}_{2}$ eq, dan $\mathrm{N}_{2} \mathrm{O} 0,047 \mathrm{Kg}$ setara dengan $12,57 \mathrm{Kg}-\mathrm{CO}_{2}$ eq. 
Tabel 5. Estimasi Emisi GRK CV. Gunung Betung per bulan dan per tahun untuk kapasitas produksi 1 ton buah kopi per hari

\begin{tabular}{lccc}
\hline Tahapan Proses & Per Hari & $\begin{array}{c}\text { Emisi GRK } \mathbf{C O}_{\mathbf{2}} \mathbf{e q}(\mathbf{K g}) \\
\text { Per Bulan }\end{array}$ & Per Tahun \\
\hline Pemupukan & 12,46 & 311 & 3.738 \\
Transportasi & 14,30 & 357 & 4.289 \\
Sortasi manual I & 0,84 & 21 & 252 \\
Pengupasan kulit tanduk & 15,73 & 393 & 4.719 \\
Sortasi manual II & 0,84 & 21 & 252 \\
Roasting / peyangraian & 23,96 & 599 & 7.187 \\
Pendinginan I & 2,40 & 60 & 720 \\
Grinding / penggilingan & 14,30 & 358 & 4.290 \\
Pendinginan II & 2,40 & 60 & 720 \\
Packing/ pengemasan & 5,96 & 149 & 1.788 \\
Penyimpanan & 2,40 & 60 & 720 \\
Total & $\mathbf{9 5 , 5 8}$ & $\mathbf{2 . 3 8 9}$ & $\mathbf{2 8 . 6 7 4}$ \\
\hline
\end{tabular}

Emisi GRK dari pengolahan pabrik didominasi oleh gas $\mathrm{CO}_{2}$, dengan total potensi GWP $\left(\mathrm{CO}_{2}, \mathrm{CH}_{4}\right.$, dan $\mathrm{N}_{2} \mathrm{O}$ ) sebesar $95,58 \mathrm{Kg}-\mathrm{CO}_{2} \mathrm{eq} /$ ton buah kopi yang diolah atau $0,42 \mathrm{Kg}-\mathrm{CO}_{2} \mathrm{eq} / \mathrm{Kg} \mathrm{kopi}$ bubuk. Nilai emisi GRK dari pengolahan kopi tersebut cukup baik karena dari hasil perhitungan menunjukkan masih jauh di bawah standar yang telah diatur dalam Permenperin No.54 Tahun 2020 yaitu maksimum 3,75 ton $\mathrm{CO}_{2}$ eq/ton produk atau $3,75 \mathrm{Kg} \mathrm{CO}$ eq/Kg produk (Kemenperin, 2020).

Berdasarkan hasil perhitungan pada Tabel 5 rata-rata produksi kopi robusta secara kering CV. Gunung Betung jika diasumsikan produktifitasnya konstan maka dapat dihitung total emisi GRK yang dihasilkan perbulan sebesar $2.389 \mathrm{Kg}-\mathrm{CO}_{2} \mathrm{eq}$ atau per tahun sebesar $28.674 \mathrm{Kg}-\mathrm{CO}_{2} \mathrm{eq}$.

\section{Kesimpulan}

Potensi produksi bersih yang dapat diterapkan di CV. Gunung Betung diantaranya adalah pembuatan dome penjemuran buah kopi dengan drying beds (PBP 3,18 bulan dan investasi Rp. 2.285.000), pengadaan mesin genset (PBP 1,16 bulan dan investasi Rp. 5.860.000), pembuatan sirkulasi udara pada ruang roasting dengan exhaust fan (PBP 0,07 bulan dan investasi Rp. 1.268.000), pembuatan reaktor untuk pengomposan limbah padat (PBP 2,18 bulan dan investasi Rp. 3.440.000) dan penambahan alat packing (PBP 0,45 bulan dan investasi Rp. 3.057.000). Penentuan opsi produksi bersih akan diterapkan melalui analisis aspek teknis, lingkungan, dan finansial yang sesuai dengan kriteria serta kesanggupan dari pemilik industri dari hasil diskusi. Hasil penilaian daur hidup proses produksi kopi robusta secara kering menunjukkan bahwa pengolahan $1.000 \mathrm{~kg}$ buah kopi memerlukan energi sebesar 869,92 MJ dan menghasilkan emisi GRK sebesar 95,58 Kg CO2-eq/ ton buah kopi atau 0,42 Kg CO2-eq/ kg bubuk setara dengan $2.389 \mathrm{Kg} \mathrm{CO} 2-\mathrm{eq} / \mathrm{bulan}$ dan $28.674 \mathrm{Kg} \mathrm{CO}$-eq/tahun.

\section{Daftar Pustaka}

Adiansyah, J. S., Ningrum, N. P., Pratiwi, D., \& Hadiyanto, H. (2019). Kajian daur hidup (life cycle assessment) dalam produksi pupuk urea: studi kasus PT Pupuk Kujang. Jurnal Ilmu Lingkungan, 17(3), 522. https://doi.org/10.14710/jil.17.3.522-527

AEKI. (2016). Asosiasi eksportir kopi Indonesia. Laporan pasar kopi (Report of coffee market). Edisi Juli 2016. http://www.aeki-aice.org/statistic aeki.html

Fauzi, A. M., Ainy, R.,\& Yaoi, H. (2018). Study on cleaner production strategy in the small scale tapioca industry: a case study in Kelurahan Ciluar, North Bogor sub-district. Journal of Agroindustrial Technology, 18(2), 60-65. 
BPS. (2018). Badan Pusat Statistik. Statistik kopi indonesia. Indonesian Coffe Statistic 2018. https://www.bps.go.id/publication/2019/12/06/b5e163624c20870bb3d6443a/statistik-kopiindonesia-2018.html

Chemura, A., Mahoya, C., Chidoko, P., \& Kutywayo, D. (2017). Effect of soil moisture deficit stress on biomass accumulation of four coffee ( Coffea arabica) varieties in Zimbabwe. ISRN Agronomy, 2014, 110. https://doi.org/10.1155/2017/767312

De Marco, I., Riemma, S., \& lannone, R. (2018). Life cycle assessment of supercritical $\mathrm{CO}_{2}$ extraction of caffeine from coffee beans. Journal of Supercritical Fluids, 133(November 2017), 393-400. https://doi.org/10.1016/j.supflu.2017.11.005

Ditjenbun. (2019). Direktorat Jenderal Perkebunan. Stastistik perkebunan kopi Indonesia 2019. http://ditjenbun.pertanian.go.id/?publikasi=buku-statistik-perkebunan-2019-2021.

Diyarma, I., \& Bantacut, T. (2019). Assessment of environmental impact of the gayo arabica coffee production by wet process using life cycle assessment. Acta Universitatis Cibiniensis. Series E: Food Technology, 23(1), 27-34. https://doi.org/10.2478/aucft-2019-0004

Echeverria, M. C., \& Nuti, M. (2017). Valorisation of the residues of coffee agro-industry: perspectives and limitations. The Open Waste Management Journal, 10(1), 13-22. https://doi.org/10.2174/1876400201710010013

Edowai, D. N., \& Tahoba, A. E. (2018). Proses produksi dan uji mutu bubuk kopi arabika (Coffea arabica L) asal kabupaten Dogiyai, Papua. AGRIOVET, 1(1), 1-18, ISSN 2716-4403.

Fadhil, R., Maarif, M. S., Bantacut, T., \& Hermawan, A. (2017). Model strategi pengembangan sumber daya manusia agroindustri kopi gayo dalam menghadapi masyarakat ekonomi ASEAN. Jurnal Manajemen Teknologi, 16(2), 141-155. https://doi.org/10.12695/jmt.2017.16.2.3

Fitriyanti, R. (2018). Penerapan produksi bersih pada industri pulp dan kertas. Jurnal Redoks, 1(2), 16. https://doi.org/10.31851/redoks.v1i2.2025

Hakim, M. A. R. (2018). Kajian implementasi produksi bersih di industri pengolahan kopi (studi kasus cV frinsa agrolestari, Bandung). Institut Pertanian Bogor. https://repository.ipb.ac.id/handle/123456789/95558

Hartatik, W., \& Widowati, L., R. (2006). Pupuk organik dan pupuk hayati. Bogor. ISBN : 978-979-9474-57-5.

Hassard, H. A., Couch, M. H., Techa-Erawan, T., \& Mclellan, B. C. (2016). Product carbon footprint and energy analysis of alternative coffee products in Japan. Journal of Cleaner Production, 73, 310-321. https://doi.org/10.1016/j.jclepro.2016.02.006

ICO. (2017).International Coffe Organization. Statistic on Coffee. https://www.ico.org/trade statistics

IPCC. (2006). Intergovernmental panel on climate change. Guidelines for national greenhouse gas inventories, volume 5 waste, chapter 6 wastewater treatment and discharge. https://www.ipccnggip.iges.or.jp/public/2006gl/pdf/5 Volume5/V5 6 Ch6 Wastewater.pdf

Jepngetich Maina, J. (2017). Evaluation and mitigation of greenhouse gas emissions from the smallholder coffee chain in $\quad$ Kenya. May, 110. https://pdfs.semanticscholar.org/d0c9/a7568127d7fd5f52b55ff8254b0e02147f10.pdf

Kemenperin. (2020). Kementerian Perindustrian Indonesia. Peraturan menteri perindustrian Republik Indonesia nomor 54 tahun 2020 tentang standar industri hijau untuk industri pengolahan kopi instan. 10 November 2020. http://jdih.kemenperin.go.id/site/template3/2704.

Ledy, D. S., Haryono, D., \& Situmorang, S. (2019). Analisis bauran pemasaran (marketing mix) dan strategi pengembangan (studi kasus pada agroindustri kopi bubuk cap intan di kota Bandar Lampung). Jurnal IImu-IImu Agribisnis, 7(1), 52. https://doi.org/10.23960/jiia.v7i1.52-59

Nisa, F., Haji, A. T. S., Suharto, B., \& Sumberdaya, J. (2016). Penentuan tingkat eko-efisiensi proses produksi biji kakao menggunakan life cycle assessment pada unit produksi di pusat penelitian kopi dan kakao Indonesia determination of eco-efficiency rate of cocoa beans process. Jurnal Sumberdaya Alam Dan 
Lingkungan, 32-39.

Novita, E., Suryaningrat, I. B., \& Daniati, E. (2018). Potensi penerapan produksi bersih di peternakan sapi perah Cv. Margo Utomo Kecamatan Kalibaru Kabupaten Banyuwangi. Jurnal Agroteknologi, 12(02), 116. https://doi.org/10.19184/j-agt.v12i02.9277

Nugraha, A. Z., Wiloso, E. I., \& Yani, M. (2018). Pemanfaatan serbuk gergaji sebagai substitusi bahan bakar pada proses pembakaran kiln di pabrik semen dengan pendekatan life cycle assesment (Ica). Jurnal Pengelolaan Sumberdaya Alam Dan Lingkungan (Journal of Natural Resources and Environmental Management), 8(2), 188-198. https://doi.org/10.29244/jpsl.8.2.188-198

Phrommarat, B. (2019). Life cycle assessment of ground coffee and comparison of different brewing methods: A case study of organic arabica coffee in Northern Thailand. Environment and Natural Resources Journal, 17(2), 96-108. https://doi.org/10.32526/ennrj.17.2.2019.16

Pramono, A., \& Sadmaka. (2018). Emisi gas rumah kaca, cadangan karbon serta strategi adaptasi dan mitigasi pada perkebunan kopi rakyat di Nusa Tenggara Barat (greenhouse gas emission, carbon stock, adaptation and mitigation strategies at smallholder coffee plantation in West Nusa Tenggara). E-Journal Menara Perkebunan, 86(2), 62-71. https://doi.org/10.22302/iribb.jur.mp.v86i2.294

Roy, P., Nei, D., Orikasa, T., Xu, Q., Okadome, H., Nakamura, N., \& Shiina, T. (2019). A review of life cycle assessment (LCA) on some food products. Journal of Food Engineering, 90(1), 1-10. https://doi.org/10.1016/j.jfoodeng.2019.06.016

Salomone, R. (2018). Life cycle assessment applied to coffee production : investigating environmental impacts to aid decision making for improvements at company level. Journal of Food Agriculture and Environment, April 2016. https://doi.org/https://doi.org/295-300.2018

Sirait, A. T., Noor, E., \& Ismayana, A. (2019). Penerapan produksi bersih untuk meningkatkan efisiensi proses pelapisan logam. Jurnal Pengelolaan Sumberdaya Alam Dan Lingkungan (Journal of Natural Resources and Environmental Management), 9(3), 700-709.https://doi.org/10.29244/jpsl.9.3.700-709

Siregar, K., Tambunan, A. H., Irwanto, A. K., Wirawan, S. S., \& Araki, T. (2019). A comparison of life cycle assessment on oil palm (Elaeis guineensis Jacq.) and physic nut (Jatropha curcas Linn.) as feedstock for biodiesel production in Indonesia. Energy Procedia, 65, 170-179. https://doi.org/10.1016/j.egypro.2019.01.054

Velmourougane, K. (2016). Impact of organic and conventional systems of coffee farming on soil properties and culturable microbial diversity. Scientifica, 2016. https://doi.org/10.1155/2016/3604026

Zhou, W. J., Ji, H. L., Zhu, J., Zhang, Y. P., Sha, L. Q., Liu, Y. T., Zhang, X., Zhao, W., Dong, Y. X., Bai, X. L., Lin, Y. X., Zhang, J. H., \& Zheng, X. H. (2016). The effects of nitrogen fertilization on $\mathrm{N}_{2} \mathrm{O}$ emissions from a rubber plantation.Scientific Reports, 6(January), 1-12. https://doi.org/10.1038/srep28230 